\title{
Effect of Health Coaching Delivered by a Respiratory Therapist or Nurse on Self-Management Abilities in Severe COPD: Analysis of a Large Randomized Study
}

\author{
Roberto Benzo and Charlene McEvoy
}

\begin{abstract}
BACKGROUND: Self-management of patients with COPD has received increasing attention in recent years given its association with improved outcomes. There is a scarcity of feasible interventions that can improve self-management abilities. We recently reported the positive effect of health coaching, started at the time of hospital discharge, on re-hospitalizations and emergency department visits for patients with COPD admitted for an exacerbation. In this substudy, we aimed to investigate the effects of health coaching delivered by a respiratory therapist or a nurse compared with guideline-based usual care on self-management abilities in COPD. METHODS: Self-management was measured by using the Chronic Respiratory Disease Questionnaire mastery domain and was assessed at baseline, at 6 months, and at 12 months after hospitalization. RESULTS: Two hundred and fifteen subjects hospitalized for a COPD exacerbation were randomized to the intervention or the control. The mean change in the Chronic Respiratory Disease Questionnaire mastery score from baseline to month 6 was $\Delta 0.5832 \pm 1.29$ on the intervention arm and $\Delta 0.1732 \pm 1.14$ on the control arm $(P=.02)$. Of the intervention subjects, 55\% had at least a 0.5-point increase in Chronic Respiratory Disease Questionnaire mastery (minimum clinically important difference) compared with $38 \%$ in the control group. Health coaching was an independent predictor of the minimum clinically important difference or greater change in the Chronic Respiratory Disease Questionnaire mastery score at 6 months after initiation of the intervention (odds ratio 1.95, 95\% CI 1.01-3.79). The changes in the Chronic Respiratory Disease Questionnaire mastery score at 12 months showed a trend but did not attain statistical significance. CONCLUSIONS: Health coaching delivered by a respiratory therapist or a nurse improved self-management abilities when applied to subjects with COPD after hospital discharge for an exacerbation. (ClinicalTrials.gov Identifier: NCT01058486, Mayo IRB 09-004341). Key words: Chronic Respiratory Questionnaire mastery domain; COPD; health coaching; intervention; self-management. [Respir Care 2019;64(9):1065-1072. (C) 2019 Daedalus Enterprises]
\end{abstract}

\section{Introduction}

Interventions to support COPD self-management in patients with COPD have received increasing attention over the past years given the association with improved out-

\footnotetext{
Dr Benzo is affiliated with the Mindful Breathing Laboratory, Division of Pulmonary and Critical Care Medicine, Mayo Clinic, Rochester, Minnesota. Dr McEvoy is affiliated with HealthPartners Institute for Education and Research, Bloomington, Minnesota.

Dr Benzo is funded by the National Institutes of Health National Heart, Lung, and Blood Institute R01HL140486, 1R61HL142933, and K24 HL 138150. Dr McEvoy is funded by grant RO1HL140486.
}

The authors have disclosed no conflicts of interest. comes. ${ }^{1,2}$ Self-management interventions may contain multiple interacting components in which patients are taught new skills, such as monitoring signs and symptoms to detect deterioration and adherence to treatment or lifestyle change to apply in their daily lives. There is a scarcity of feasible interventions that can improve self-management abilities. We recently reported the positive effect of health coaching that started at the time of hospital discharge, on re-hospitaliza-

\footnotetext{
Correspondence: Roberto Benzo MD MSc, Mindful Breathing Laboratory, Division of Pulmonary and Critical Care, Mayo Clinic, 200 First Street SW, Gonda 18-440, Rochester, MN 55902. E-mail: benzo.roberto@mayo.edu.
}

DOI: $10.4187 /$ respcare. 05927 
tions, and at emergency department visits in patients with COPD admitted for an exacerbation. ${ }^{3}$ We postulated that health coaching improves self-management abilities. Health coaching has the potential to improve self-management abilities primarily because it is patient-centered and rooted in a solid theoretical framework of communication and behavior change known as motivational interviewing. ${ }^{4-7}$

This was a secondary analysis of a published ${ }^{3}$ randomized clinical trial implemented in a population of subjects with COPD (hospitalized for an exacerbation) with a high risk of poor outcomes in which self-management is so critical. We investigated the effect of a simple intervention (health coaching delivered over the telephone by a respiratory therapist or a nurse) compared with usual care on a very specific outcome: self-management abilities measured by the the Chronic Respiratory Disease Questionnaire mastery domain. This domain encompasses 2 critical and recognized constructs of self-management in COPD: \#1 self-efficacy, ${ }^{8}$ to deal with breathlessness and the disease itself; and \#2 coping with emotions associated with worsening symptoms and outcomes. ${ }^{9,10}$

\section{Methods}

\section{Design Overview}

This was a secondary analysis of a published multi-site (Mayo Clinic, Rochester, Minnesota, and Health Partners Regions Hospital, Minneapolis, Minnesota), randomized trial that compared a health-coaching intervention with guideline-based usual care for subjects after a hospitalization for a COPD exacerbation. Inclusion criteria for the published multi-site effectiveness study included the following: a primary diagnosis of a COPD-related hospitalization (exacerbation or pneumonia) and the ability to interact with a coach in telephone communication.

\section{Randomization}

We randomly assigned subjects by using an online computer-generated simple binomial randomization program into the 2 groups, stratified by the center.

\section{Intervention}

Health coaches met with the subjects at least once in person after discharge with subsequent sessions conducted by telephone, once a week for the initial 3 months, and once a month thereafter. Health coaches followed a set agenda that reviewed the rationale for the study. The first visit was in person and lasted $\sim 2 \mathrm{~h}$. Visit 1 was oriented to discussing the concept of self-management, goal setting, and action planning, and the specifics of the telephone sessions to come. Each encounter embodied the spirit of motivational interviewing: the subject is the expert; the willing-

\section{QUICK LOOK}

\section{Current knowledge}

Interventions to support COPD self-management in patients with COPD have received increasing attention over the years, given the association with improved outcomes. There is a scarcity of feasible interventions that can improve self-management abilities in severe COPD.

\section{What this paper contributes to our knowledge}

This randomized study indicated that health coaching delivered by a respiratory therapist or a nurse represented a simple intervention that improved self-management abilities. The Chronic Respiratory Disease Questionnaire mastery domain was a feasible and valid method to measure the self-management process and permitted these self-management results from different interventions to be replicated.

ness of the coach to listen deeply to understand the subject and empowerment of the participant to adopt the behavior that he or she feels is important to pursue, even if not related to his or her pulmonary condition.

Coaches asked the subject what he or she already does to be more comfortable living with chronic lung disease and to be and stay healthy in general, and tried to explore future hopes and goals ${ }^{11}$ that he or she could work toward. Details of the intervention can be obtained from Table 1 and our previous open-access reports. ${ }^{3,11}$ Disease-specific health-related quality of life was measured by using the Chronic Respiratory Disease Questionnaire at baseline, 6 months, and 12 months after hospital discharge. The minimum clinically important difference accepted for this instrument is 0.5 points. The Chronic Respiratory Disease Questionnaire is a well-accepted tool to measure health status in COPD and has 4 domains: dyspnea, fatigue, emotional, and mastery. ${ }^{12}$

Self-management, the primary outcome of this substudy, was assessed by using the Chronic Respiratory Disease Questionnaire mastery domain at baseline (immediately after discharge), at 6 months, and at 12 months. Chronic Respiratory Disease Questionnaire mastery has 4 items that measure 2 key self-management abilities: (1) selfefficacy, ${ }^{8}$ and (2) panic and anxiety. ${ }^{9,10,13}$ Each item's score ranges from 1 (worst) to 7 (best). The 4 items are the following: "How often during the last 2 weeks did you have a feeling of fear or panic when you had difficulty getting your breath?"; "In the last 2 weeks, how much of the time did you feel very confident and sure that you could deal with your illness?"; "How often during the last 2 weeks did you feel you had complete control of your 


\section{Effect of Health Coaching on COPD Self-Management}

Table 1. A Brief Summary of the Intervention Content

\begin{tabular}{|c|c|}
\hline Content Outline & Additional Considerations for Interventionist \\
\hline \multicolumn{2}{|l|}{ Greeting, set agenda for session } \\
\hline \multirow{4}{*}{$\begin{array}{l}\text { Elicit participant experience and } \\
\text { opinions about the self- } \\
\text { management goals from session } 1\end{array}$} & Use O.A.R.S. \\
\hline & Listen for what they did try and what did work, affirm \\
\hline & Resist the urge to immediately attempt solving their problems and barriers \\
\hline & Connect their thoughts and behavior back to the values that they mentioned at the last session as appropriate \\
\hline \multirow{9}{*}{$\begin{array}{l}\text { Individualized, collaborative } \\
\text { conversation about physical } \\
\text { activity recommendations }\end{array}$} & Listen for ambivalence \\
\hline & $\begin{array}{l}\text { Summarize both sides of the ambivalence; start with the reasons for not changing, followed by reasons } \\
\text { for changing }\end{array}$ \\
\hline & Let me see if I understand what you've said... \\
\hline & Ask: Did I get it all? \\
\hline & Ask about the next step \\
\hline & Where does that leave you now \\
\hline & What is the next step? \\
\hline & O.A.R.S. \\
\hline & Use E-P-E when sharing information \\
\hline \multirow{5}{*}{$\begin{array}{l}\text { Describe and then discuss } \\
\text { "self-management" }\end{array}$} & Use E-P-E to describe content extracted from the self-management workbook* \\
\hline & Discuss the use of the book in general \\
\hline & Discuss how the concept of self-management connects to patient values and strengths, if appropriate \\
\hline & Listen for change talk, respond with O.A.R.S. \\
\hline & Collaborate in setting goal for participants to read chapter 2 of workbook* before the next session \\
\hline \multirow{5}{*}{$\begin{array}{l}\text { Review the Self-Management } \\
\text { Action Plan }\end{array}$} & Elicit patients' thoughts about the self-management domains included and the format in general \\
\hline & Discuss the process of action planning \\
\hline & $\begin{array}{l}\text { Discuss patients' role in collaborative action planning in the session and experimenting with action plans } \\
\text { out of the session }\end{array}$ \\
\hline & Use E-P-E when providing information about domains \\
\hline & Listen for ambivalence about various self- management behaviors; respond with O.A.R.S. \\
\hline \multirow{7}{*}{$\begin{array}{l}\text { Collaborate in creating action } \\
\text { plan on the Self-Management } \\
\text { Action Plan form (most often, } \\
\text { physical activity at session 2) }\end{array}$} & $\begin{array}{l}\text { Elicit patients' preferences and/or desires for behavior change, eg, "What would you be willing to try } \\
\text { before our next meeting with (the self-management area they selected)?" }\end{array}$ \\
\hline & Elicit patients' choice, do not assign goals, use the patients' language to describe the goal \\
\hline & Assess confidence for goal completion \\
\hline & Listen for ambivalence about the action planning process or self-management behavior itself \\
\hline & O.A.R.S. \\
\hline & Listen for and respond to change talk \\
\hline & Connect goals to patients' values, strengths, and priorities when possible \\
\hline \multirow{4}{*}{$\begin{array}{l}\text { Elicit participants' thoughts } \\
\text { and feelings about the } \\
\text { session }\end{array}$} & O.A.R.S., eg, "What seems most personally relevant to you of all that we discussed today?" \\
\hline & Reaffirm commitment to action plan and express optimism, eg, "Is that what you plan to do?" \\
\hline & Listen for ambivalence \\
\hline & If the clients are ambivalent, then use O.A.R.S. and collaborate in problem solving if appropriate \\
\hline \multicolumn{2}{|l|}{$\begin{array}{l}\text { Briefly describe what patients } \\
\text { can expect in session } 3 \text { and } \\
\text { close the session }\end{array}$} \\
\hline
\end{tabular}

breathing problems?"; and "How often during the last 2 weeks did you feel upset or scared when you had difficulty getting your breath?"

\section{Control Group: Guideline-Based Usual Care}

Both the intervention arm and usual care group received care by following the Global Initiative for Chronic Ob- structive Lung Disease and were also referred to conventional pulmonary rehabilitation. ${ }^{14}$

\section{Data and Safety Monitoring}

The National Institutes of Health that funded this study required a data and safety monitoring board to monitor 
Table 2. Logistic Model to Determine the Predictive Validity of Chronic Respiratory Disease Questionnaire Mastery at Baseline for Hospitalizations at Different Time Points After Hospital Discharge, Adjusted by Significant Covariates

\begin{tabular}{lc}
\hline \multicolumn{1}{c}{ End Point } & $\begin{array}{c}P, \text { Adjusted for Arm, Age, } \\
\text { and mMRC }\end{array}$ \\
\hline Any hospitalization at & .04 \\
1 mo & .05 \\
3 mo & \\
COPD hospitalization at & .01 \\
1 mo & .01 \\
3 mo & .02 \\
6 mo & .04 \\
12 mo & .01 \\
Death or COPD hospitalization at & .01 \\
1 mo & .03 \\
3 mo & .03 \\
6 mo & \\
12 mo & \\
\hline mMRC $=$ Modified Medical Research Council dyspnea scale \\
\hline
\end{tabular}

subject accrual, outcomes, complications, and protocol adherence.

\section{Statistical Analysis}

The a priori primary end point for this substudy was the change in Chronic Respiratory Disease Questionnaire mastery at 6 months of initiating the intervention (health coaching). Changes from baseline to 6 months were compared between the study arms by using 2-sample, 2-sided $t$ tests with $5 \%$ type-1 error rates. Logistic models were used to assess the impact of treatment arm (health coaching) on 6-month Chronic Respiratory Disease Questionnaire mastery after adjusting for age and dyspnea (modified Medical Research Council dyspnea scale), the corresponding baseline measures with univariate significance. The sensitivity of these models was evaluated by using 10,000 bootstrapped samples. Because there were very few missing values and the results from intent-to-treat analyses were similar to the original analyses, no imputations were done. The predictive validity for the Chronic Respiratory Disease Questionnaire mastery was tested by measuring its independent association with a COPD re-hospitalization (Table 2). Multivariate models included the univariate predictors. Analyses were done by using SAS version 9.4 (SAS Institute, Cary, North Carolina).

\section{Results}

A total of 215 subjects hospitalized for a COPD exacerbation were randomized to the intervention or the control.
The baseline measures for the intervention and control groups are summarized in Table 3. The mean change in the Chronic Respiratory Disease Questionnaire mastery score from baseline to month 6 was $\Delta 0.5832 \pm 1.29$ in the intervention arm and $\Delta 0.1732 \pm 1.14$ in the other $\operatorname{arm}(P=.02)$ (Fig. 1$)$. Of the intervention subjects, $55 \%$ had at least a 0.5 increase in Chronic Respiratory Disease Questionnaire mastery score compared with $38 \%$ of the control group (Number Needed to Treat $=5$ ). At 12 months after the intervention initiation, there was no statistically significant difference in the score: $\Delta 0.532 \pm 1.3$ in the intervention arm and $\Delta 0.1732 \pm 1.1 \mathrm{in}$ the control group $(P=.29)$. In a logistic model that aimed to predict a $\geq 0.5$ change in the Chronic Respiratory Disease Questionnaire mastery score at 6 months after the intervention's initiation, health coaching was as an independent predictor (odds ratio 1.95, 95\% CI 1.01-3.79) after adjusting for age, lung function $\left(\mathrm{FEV}_{1} \%\right)$ and baseline Chronic Respiratory Disease Questionnaire dyspnea score (C statistic 0.66).

Predictive Validity of Chronic Respiratory Disease Questionnaire Mastery. At baseline, the Chronic Respiratory Disease Questionnaire mastery score was independently associated with hospitalizations (an outcome reported as associated with self-management ${ }^{15}$ ) and is detailed in Table 2. Being a nurse or a respiratory therapist made no difference in the success of the intervention.

\section{Discussion}

We recently reported the effectiveness of health coaching in decreasing re-hospitalizations and emergency department visits, and in improving the quality of life up to 12 months in subjects with COPD after the hospital discharge. ${ }^{3,16}$ This report extended our initial publication by suggesting that health coaching delivered by a respiratory therapist or a nurse improved self-management abilities as measured by the Chronic Respiratory Disease Questionnaire mastery at 6-month after hospitalization. The improvement in self-management abilities was beyond the minimum clinically important difference $(>0.5$ points) at 6 months after hospital discharge. There are not many feasible and effective interventions that improve self-management abilities. For example: pulmonary rehabilitation improves self-management abilities but has poor uptake in the post-hospitalization setting. Jones et $\mathrm{al}^{17}$ reported that only $10 \%$ of subjects referred to pulmonary rehabilitation after a hospital stay complete the program (even in a system that covers the costs and transportation). In the outpatient setting, many patients cannot access pulmonary rehabilitation because of transportation, cost, or frailty. ${ }^{18}$

In addition to the lack of effective self-management interventions, the process of self-management is not commonly measured in clinical trials as an outcome. The currently available scales, self-management ability scale ${ }^{19}$ the 
Table 3. Baseline Clinical and Demographic Characteristics

\begin{tabular}{|c|c|c|}
\hline Characteristic & Control $(n=107)$ & Intervention $(n=108)$ \\
\hline Age, mean \pm SD y & $68.1 \pm 9.2$ & $67.9 \pm 9.8$ \\
\hline \multicolumn{3}{|l|}{ Site, mean $n(\%)$} \\
\hline Health Partners & $52(49)$ & $52(48)$ \\
\hline Mayo & $55(51)$ & $56(52)$ \\
\hline Post-secondary education, mean $n(\%)$ & $48(48)$ & $55(54)$ \\
\hline Married, mean $n(\%)$ & $48(46)$ & $54(50)$ \\
\hline Men, mean $n(\%)$ & $51(48)$ & $46(43)$ \\
\hline Continuous supplemental oxygen, mean (\%) & $32(34)$ & $40(40)$ \\
\hline Supplemental oxygen, mean $(\%)$ & $49(51)$ & $54(53)$ \\
\hline \multicolumn{3}{|l|}{ Steroid and/or antibiotic use, mean (\%) } \\
\hline For COPD, in the past $3 \mathrm{mo}$ & $78(87)$ & $89(91)$ \\
\hline In the past $3 \mathrm{mo}(\geq 2)$ & $42(48)$ & $38(40)$ \\
\hline For COPD, in the past $12 \mathrm{mo}$ & $79(90)$ & $83(86)$ \\
\hline In the past $12 \mathrm{mo}(\geq 2)$ & $61(71)$ & $61(69)$ \\
\hline \multicolumn{3}{|l|}{ Health care utilization, mean (\%) } \\
\hline Hospitalization in the past $12 \mathrm{mo}$ & $55(60)$ & $56(57)$ \\
\hline ED visit in the past $12 \mathrm{mo}$ & $52(59)$ & $54(56)$ \\
\hline Hospitalized and/or ED visit in the past 3 mo & $38(43)$ & $47(48)$ \\
\hline Hospitalized and/or ED visit, COPD related & $27(82)$ & $37(82)$ \\
\hline $\mathrm{FEV}_{1} \%$ predicted, mean $\pm \mathrm{SD}$ & $40.3 \pm 17.2$ & $40.5 \pm 17.1$ \\
\hline Total lung capacity, mean \pm SD & $115.2 \pm 25.2$ & $110.0 \pm 24.4$ \\
\hline Residual volume, mean $\pm \mathrm{SD}$ & $173.7 \pm 58.0$ & $174.6 \pm 72.8$ \\
\hline $\mathrm{D}_{\mathrm{LCO}}$, mean $\pm \mathrm{SD}$ & $38.7 \pm 23.1$ & $35.8 \pm 19.3$ \\
\hline \multicolumn{3}{|l|}{ mMRC score, mean $(\%)$} \\
\hline 0 & $3(3)$ & $2(2)$ \\
\hline 1 & $18(20)$ & $11(12)$ \\
\hline 2 & $9(10)$ & $12(13)$ \\
\hline 3 & $51(57)$ & $62(67)$ \\
\hline 4 & $9(10)$ & $6(6)$ \\
\hline Comorbidity Index score, mean $\pm \mathrm{SD}$ & $2.4 \pm 1.3$ & $2.8 \pm 1.5$ \\
\hline \multicolumn{3}{|c|}{ Chronic Respiratory Disease Questionnaire score, mean \pm SD } \\
\hline Dyspnea & $4.4 \pm 1.4$ & $4.4 \pm 1.2$ \\
\hline Fatigue & $3.7 \pm 1.3$ & $3.6 \pm 1.2$ \\
\hline Emotional & $4.7 \pm 1.4$ & $4.6 \pm 1.2$ \\
\hline Mastery & $4.6 \pm 1.5$ & $4.4 \pm 1.4$ \\
\hline Physical & $4.1 \pm 1.2$ & $4.1 \pm 1.1$ \\
\hline Daily steps, mean $\pm \mathrm{SD}$ & $2,789.9(3,000.7)$ & $2,448.0(2,030.7)$ \\
\hline Physical activity level, mean \pm SD & $1.3(0.2)$ & $1.3(0.2)$ \\
\hline Time sedentary $(<2$ METS $)$, mean \pm SD & $1,220.5(175.5)$ & $1,239.8(125.0)$ \\
\hline Time light activity (2-4 METS), mean \pm SD & $130.0(107.5)$ & $133.4(115.5)$ \\
\hline Time mod activity (4-6 METS), mean \pm SD & $14.0(29.0)$ & $8.0(12.6)$ \\
\hline Time vigorous activity ( $>6$ METS), mean \pm SD & $0.7(2.5)$ & $0.3(0.9)$ \\
\hline Resting metabolic rate, mean $\pm \mathrm{SD}$ & $1,590.3(379.4)$ & $1,529.8(309.7)$ \\
\hline Total energy expenditure, mean \pm SD & $2,069.8(495.5)$ & $2,016.7(442.8)$ \\
\hline \multicolumn{3}{|l|}{$\begin{array}{l}\mathrm{ED}=\text { emergency department } \\
\mathrm{FEV} \mathrm{V}_{1}=\text { forced expiratory volume in the first second } \\
\mathrm{D}_{\mathrm{LCO}}=\text { diffusing capacity of the lung for carbon monoxide } \\
\text { mMRC = Modified Medical Research Council Dyspnea Scale } \\
\text { METS = metabolic equivalent }\end{array}$} \\
\hline
\end{tabular}

COPD self-efficacy scale,${ }^{20}$ the self-management for COPD scale, ${ }^{21}$ and the PRAISE scale, ${ }^{22}$ are not used consistently in the clinical trials that had positive results: measuring the self-management process is just missed, which creates a knowledge gap in this important outcome. ${ }^{15}$ To promote a more prevalent measure of self-management, there is a need for a simpler and shorter valid self-management measure that can be used not only in research but in 


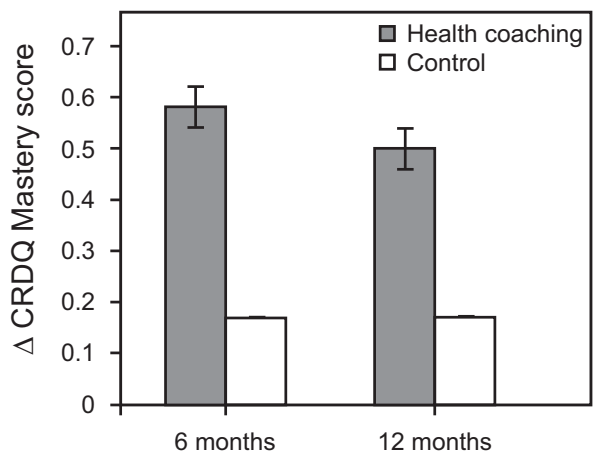

Fig. 1. Change in the Chronic Respiratory Disease Questionnaire (CRDQ) mastery score after hospital discharge in the health coaching arm and in the control arm.

daily practice. In summary, previous reports that documented the beneficial effect of self-management on health-care outcomes ${ }^{15,23,24}$ have not been able to document a measure of the self-management process itself or its improvement.

Chronic Respiratory Disease Questionnaire mastery is a good candidate for a self-efficacy measure. It has face validity to measure the self-management process, since measure self-efficacy to deal with COPD, a key measure in the selfmanagement theory. ${ }^{8}$ The Chronic Respiratory Disease Questionnaire mastery also measures the ability to cope with difficult and clinically important emotions related to dyspnea. Emotions have been reported to be independently associated with several COPD outcomes, including hospitalizations. ${ }^{10}$ We demonstrated that Chronic Respiratory Disease Questionnaire mastery had convergent validity in COPD as associated with hospitalizations (Table 2).

\section{Why Is This Study Meaningful?}

In light of the scarcity of feasible methods to improve self-management abilities in COPD, health coaching delivered by a respiratory therapist or a nurse seems a simple intervention that improves self-management. The universal availability of health coaching training and the simplicity of the self-management measure by Chronic Respiratory Disease Questionnaire mastery permits these results to be replicated.

Previous randomized controlled studies on COPD selfmanagement either were unable to demonstrate a decrease in exacerbations or hospitalization rates, or were associated with an increase in mortality. ${ }^{25-28}$ Several studies did not measure the process ${ }^{15} 29$ which left the selfmanagement process unknown, or there was no difference in self-management. ${ }^{23,27,30}$ Importantly, the study by Bischoch et al, ${ }^{30}$ which was unable to show a difference in hospitalization rates, used the same measure of self-management, the Chronic Respiratory Disease Questionnaire mastery, and found no significant differences. In our study, health coaching not only showed effectiveness in decreasing re-hospitalizations and improving quality of life but also the meaningfully improved Chronic Respiratory Disease Questionnaire mastery score. Recently, it was reported that the implementation of a self-management program for patients with advanced COPD reduced exacerbations that required hospital care. ${ }^{31}$ The latter indicates that health coaching may improve self-management abilities as we hypothesized. On the contrary, our results were opposed to a recent report that states that supported self-management did not reduce readmission rates at 3 months compared with usual care. ${ }^{32}$ We hypothesized that the degree of engagement attained between the patient and the coach we found in our intervention, ${ }^{16}$ perhaps supported by the style of communication used through motivational interviewing, was key to our success; however, we acknowledge that our results need replication, which continues to be a limitation in the evidence related to health coaching in COPD.

\section{Limitations}

We acknowledge that Chronic Respiratory Disease Questionnaire mastery is not as comprehensive as other measures of self-management, such as the COPD Self-Efficacy Scale $^{20}$ or the 30-item Self-Management Ability Scale. ${ }^{33}$ However, the Chronic Respiratory Disease Questionnaire mastery construct includes 2 unquestionable selfmanagement abilities: self-efficacy and coping with emotions indicating its face validity. The Chronic Respiratory Disease Questionnaire mastery association at baseline to short-term re-hospitalization (a well-reported outcome on self-management) indicated its predictive validity.

The lack of improvement of self-management abilities with health coaching at 12 months can be seen as a limitation. However, this was also observed with COPD rehospitalization. ${ }^{3}$ We believe that the decrease of health coaching frequency at 3-month after hospital discharge most likely explained the lack of effect at 12 months. Much like other behavioral interventions, for example, pulmonary rehabilitation, its effects fade with time when there is a lack of maintained support. It is possible, as we proposed in the original article, ${ }^{3}$ that some individuals need prolonged self-management support through health coaching to maintain the benefits.

\section{Lessons Learned}

This work left specific and impactful lessons that were "transpired" in our previous publications about health coaching ${ }^{3,16,34}$ but that we would like to summarize here for the benefit of the reader and the dissemination of health coaching itself as clinical practice in COPD. First, health 
coaching is feasible. Second, motivational interviewing provides a solid structure to teach coaches to communicate kindly and effectively. Third, participants learn to recognize changes in COPD symptoms that might indicate onset of an exacerbation and, importantly, they learn through the conversations with the health coach to have an action plan to deal with exacerbations (the latter includes the use of mindful pursed-lip breathing for better breathing and relaxation, and a medication plan that includes nebulization antibiotics and prednisone). Fourth, we envision the implementation of health coaching in practice by using currently available "Complex Care Management Codes (CPT 99487, 99489, and 99490)" now supported by Medicare that can make health coaching feasible and at no or minimum cost for the patient. We are currently actively working on such implementation.

\section{Conclusions}

Health coaching based on motivational interviewing principles may improve clinically meaningful self-management abilities: self-efficacy to deal with COPD and to cope with difficult emotions. The reported improvement in self-management abilities, its feasibility, and its effectiveness make health coaching a candidate intervention to incorporate not only in the post-hospitalization period but in other settings, such as ambulatory COPD care and pulmonary rehabilitation. We propose the Chronic Respiratory Disease Questionnaire mastery as a simple measure of self-management abilities given its validity and frequency of use in many practice settings and clinical trials. Addressing mindful patient communication not only can improve health-care utilization outcomes but also emotional and social outcomes, for example, loneliness, which has become an important risk factor for morbidity in COPD and our society. ${ }^{35}$

\section{REFERENCES}

1. Effing TW, Vercoulen JH, Bourbeau J, Trappenburg J, Lenferink A, Cafarella $\mathrm{P}$, et al. Definition of a COPD self-management intervention: International Expert Group consensus. Eur Respir J 2016;48(1): 46-54.

2. Spruit MA, Singh SJ, Garvey C, Zu Wallack R, Nici L, Rochester C, et al.; ATS/ERS Task Force on Pulmonary Rehabilitation. An official American Thoracic Society/European Respiratory Society statement: key concepts and advances in pulmonary rehabilitation. Am J Respir Crit Care Med 2013;188(8):e13-64.

3. Benzo R, Vickers K, Novotny PJ, Tucker S, Hoult J, Neuenfeldt P, et al. Health coaching and chronic obstructive pulmonary disease re-hospitalization: a randomized study. Am J Respir Crit Care Med 2016;194(6):672-680.

4. Boardman T, Catley D, Grobe JE, Little TD, Ahluwalia JS. Using motivational interviewing with smokers: do therapist behaviors relate to engagement and therapeutic alliance? J Subst Abuse Treat 2006;31(4):329-339.
5. Borrelli B, Riekert KA, Weinstein A, Rathier L. Brief motivational interviewing as a clinical strategy to promote asthma medication adherence. J Allergy Clin Immunol 2007;120(5):1023-1030.

6. Miller W. RS. Motivational interviewing: Helping People Change. In William RM, Stephen R (Applications of Motivational Interviewing). 3rd edition. New York, New York: The Guilford Press; 2013: 335-351.

7. Miller WR, Yahne CE, Moyers TB, Martinez J, Pirritano M. A randomized trial of methods to help clinicians learn motivational interviewing. J Consult Clin Psychol 2004;72(6):1050-1062.

8. Bandura A. Self-efficacy: toward a unifying theory of behavioral change. Psychol Rev 1977;84(2):191-215.

9. Benzo RP, Kirsch JL. Emotional Intelligence in COPD: The Impact on Self-Management Abilities and Quality of Life, American Thoracic Society International Conference, Denver, CO, May 15-20, 2015.

10. Abascal-Bolado B, Novotny PJ, Sloan JA, Karpman C, Dulohery MM, Benzo RP. Forecasting COPD hospitalization in the clinic: optimizing the chronic respiratory questionnaire. Int $\mathrm{J}$ Chron Obstruct Pulmon Dis 2015;10:2295-2301.

11. Benzo R, Vickers K, Ernst D, Tucker S, McEvoy C, Lorig K. Development and feasibility of a self-management intervention for chronic obstructive pulmonary disease delivered with motivational interviewing strategies. J Cardiopulm Rehabil Prev 2013;33(2):113123.

12. Williams JE, Singh SJ, Sewell L, Guyatt GH, Morgan MD. Development of a self-reported Chronic Respiratory Questionnaire (CRQSR). Thorax 2001;56(12):954-959.

13. Panagioti M, Scott C, Blakemore A, Coventry PA. Overview of the prevalence, impact, and management of depression and anxiety in chronic obstructive pulmonary disease. Int J Chron Obstruct Pulmon Dis 2014;9:1289-1306.

14. Vestbo J, Hurd SS, Agusti AG, Jones PW, Vogelmeier C, Anzueto A, et al. Global strategy for the diagnosis, management, and prevention of chronic obstructive pulmonary disease: GOLD executive summary. Am J Respir Crit Care Med 2013;187(4):347-365.

15. Bourbeau J, Julien M, Maltais F, Rouleau M, Beaupré A, Bégin R, et al.; Chronic Obstructive Pulmonary Disease axis of the Respiratory Network Fonds de la Recherche en Santé du Québec. Reduction of hospital utilization in patients with chronic obstructive pulmonary disease: a disease-specific self-management intervention. Arch Intern Med 2003;163(5):585-591.

16. Benzo RP, Kirsch JL, Hathaway JC, McEvoy CE, Vickers KS. Health coaching in severe COPD after a hospitalization: a qualitative analysis of a large randomized study. Respir Care 2017;62(11):14031411.

17. Jones SE, Green SA, Clark AL, Dickson MJ, Nolan AM, Moloney $\mathrm{C}$, et al. Pulmonary rehabilitation following hospitalisation for acute exacerbation of COPD: referrals, uptake and adherence. Thorax 2014; 69(2):181-182.

18. Keating A, Lee A, Holland AE. What prevents people with chronic obstructive pulmonary disease from attending pulmonary rehabilitation? A systematic review. Chron Respir Dis 2011;8(2):89-99.

19. Benzo RP, Abascal-Bolado B, Dulohery MM. Self-management and quality of life in chronic obstructive pulmonary disease (COPD): the mediating effects of positive affect. Patient Educ Couns 2016;99(4): 617-623.

20. Bentsen SB, Wentzel-Larsen T, Henriksen AH, Rokne B, Wahl AK. Self-efficacy as a predictor of improvement in health status and overall quality of life in pulmonary rehabilitation-an exploratory study. Patient Educ Couns 2010;81(1):5-13.

21. Zhang C, Wang W, Li J, Cai X, Zhang H, Wang H, Wang X. Development and validation of a COPD self-management scale. Respir Care 2013;58(11):1931-1936. 


\section{Effect of Health Coaching on COPD Self-Management}

22. Vincent E, Sewell L, Wagg K, Deacon S, Williams J, Singh S. Measuring a change in self-efficacy following pulmonary rehabilitation: an evaluation of the PRAISE tool. Chest 2011;140(6):15341539.

23. Bucknall CE, Miller G, Lloyd SM, Cleland J, McCluskey S, Cotton $\mathrm{M}$, et al. Glasgow supported self-management trial (GSuST) for patients with moderate to severe COPD: randomised controlled trial. BMJ 2012;344:e1060.

24. Rice KL, Dewan N, Bloomfield HE, Grill J, Schult TM, Nelson DB, et al. Disease management program for chronic obstructive pulmonary disease: a randomized controlled trial. Am J Respir Crit Care Med 2010;182(7)890-896.

25. Fan VS, Gaziano JM, Lew R, Bourbeau J, Adams SG, Leatherman $\mathrm{S}$, et al. A comprehensive care management program to prevent chronic obstructive pulmonary disease hospitalizations: a randomized, controlled trial. Ann Intern Med 2012;156(10):673-683.

26. Mitchell KE, Johnson-Warrington V, Apps LD, Bankart J, Sewell L, Williams JE, et al. A self-management programme for COPD: a randomised controlled trial. Eur Respir J 2014;44(6):1538-1547.

27. Trappenburg JC, Monninkhof EM, Bourbeau J, Troosters T, Schrijvers AJ, Verheij TJ, Lammers JW. Effect of an action plan with ongoing support by a case manager on exacerbation-related outcome in patients with COPD: a multicentre randomised controlled trial. Thorax 2011;66(11):977-984.

28. Monninkhof E, van der Valk P, van der Palen J, van Herwaarden C, Zielhuis G. Effects of a comprehensive self-management programme in patients with chronic obstructive pulmonary disease. Eur Respir J 2003;22(5):815-820.
29. Gadoury MA, Schwartzman K, Rouleau M, Maltais F, Julien M, Beaupré A, et al.; Chronic Obstructive Pulmonary Disease axis of the Respiratory Health Network, Fonds de la recherche en santé du Québec (FRSQ). Self-management reduces both short- and long-term hospitalisation in COPD. Eur Respir J 2005;26(5):853857.

30. Bischoff EW, Akkermans R, Bourbeau J, van Weel C, Vercoulen JH, Schermer TR. Comprehensive self management and routine monitoring in chronic obstructive pulmonary disease patients in general practice: randomised controlled trial. BMJ 2012;345:e7642.

31. Sánchez-Nieto JM, Andújar-Espinosa R, Bernabeu-Mora R, Hu C, Gálvez-Martínez B, Carrillo-Alcaraz A, et al. Efficacy of a selfmanagement plan in exacerbations for patients with advanced COPD. Int J Chron Obstruct Pulmon Dis 2016;11:1939-1947.

32. Johnson-Warrington V, Rees K, Gelder C, Morgan MD, Singh SJ. Can a supported self-management program for COPD upon hospital discharge reduce readmissions? A randomized controlled trial. Int J Chron Obstruct Pulmon Dis 2016;11:1161-1169.

33. Cramm JM, Strating MM, de Vreede PL, Steverink N, Nieboer AP. Validation of the self-management ability scale (SMAS) and development and validation of a shorter scale (SMAS-S) among older patients shortly after hospitalisation. Health Qual Life Outcomes 2012;10:9.

34. Rehman H, Karpman C, Vickers Douglas K, Benzo RP. Effect of a motivational interviewing-based health coaching on quality of life in subjects with COPD. Respir Care 2017;62(8):1043-1048.

35. Benzo R. Satori: awakening to outcomes that matter: the impact of social support in chronic obstructive pulmonary disease. Ann Am Thorac Soc 2017;14(9):1385-1386. 